\title{
Medical marijuana-an obesity problem or opportunity?
}

\author{
Frank L. Greenway $\mathbb{1}^{1} \cdot$ John P. Kirwan ${ }^{1}$
}

Received: 11 January 2019 / Accepted: 20 January 2019 / Published online: 12 February 2019

(c) Springer Nature Limited 2019

Marijuana for medical or recreational use is now legal in 33 of the 50 United States (US) and in the District of Columbia. Since marijuana had previously been illegal, and still is at the federal level, marijuana research has been limited with a few notable exceptions.

On the surface, one might assume that marijuana would only exacerbate the obesity epidemic as increased appetite is a well-known side effect; however, initial obesity research suggests that this assumption may be premature. Previous obesity research examined rimonabant, a cannabinoid-1 (CB1) receptor inverse agonist that produced significant weight loss and improved glucose tolerance, as well as other cardiovascular risk factors. Rimonabant was never approved in the US, but it was approved in Europe only to be removed from the market due to incidences of depression and suicide [1]. It is important to note that an inverse agonist is a pharmacologic term for a medication that reduces the activity of a receptor below the baseline level, contrasted to a neutral antagonist that returns the receptor activity to the baseline level [2]. Because marijuana is known to cause euphoria and increased appetite, it is not surprising that an inverse agonist results in depression, anorexia, and weight loss.

Although marijuana is popular for its psychoactive properties, there are potentially useful components of marijuana without psychoactive properties. For example, cannabidiol (CBD), a non-psychoactive derivative of the plant, was recently approved as a treatment for two forms of rare and severe epilepsy, the Lennox-Gastaut and Dravet syndromes [3]. Tetrahydrocannabivarin (THCV), another

These authors contributed equally: Frank L. Greenway, John P. Kirwan

Frank L. Greenway

frank.greenway@pbrc.edu

1 Pennington Biomedical Research Center, 6400 Perkins Road, Baton Rouge, LA 70808, USA non-psychoactive derivative and a metabolite of tetrahydrocannabinol (THC), was first isolated in 1971 [4]. THCV is a neutral antagonist of CB1 (and possibly CB2) receptors that antagonize the psychoactive component THC $[5,6]$.

THCV in pure form, but not as an extract containing $\mathrm{CBD}$, has been shown to produce hypophagia and weight reduction at doses as low as $3 \mathrm{mg} / \mathrm{kg}$ in mice [7]. It has also been found to improve glucose tolerance, insulin sensitivity and insulin signaling in hepatocytes and myocytes from insulin-resistant diet-induced obese mice [8]. Notably, in this study, THCV did not reduce food intake or body weight; however, it is not clear whether the THCV used was in pure form or whether it was mixed with CBD in an extract.

Obesity is a condition in which the CB1 receptor is upregulated, and THCV serves as a neutral antagonist to the CB1 receptor. Therefore, THCV is not associated with the nausea or the behavioral profile associated with inverse agonists used in rat or human studies $[9,10]$. THCV was evaluated in a double-blind, placebo-controlled clinical trial in which 62 subjects with type 2 diabetes were randomized to five treatment arms: THCV in its pure form $5 \mathrm{mg}$ twice a day, CBD100 mg twice a day, combinations of THCV and $\mathrm{CBD}$, or placebo. THCV decreased fasting glucose by 12.6 $\mathrm{mg} / \mathrm{dL}(p<0.05)$, increased adiponectin $(p<0.01)$, and improved beta-cell function with only mild to moderate adverse events; however, these positive effects of THCV were lost in combination with CBD. It is not clear why the rodent study with pure parenteral THCV showed a decrease in body weight and food intake, but the oral dose of THCV in this human study did not affect body weight or food intake [11]. Rimonabant diminished neural reward responses measured by functional magnetic resonance imaging (MRI). The neural response to a rewarding (sight or flavor of chocolate) or aversive (picture of moldy strawberries and a less pleasant strawberry taste) stimulus in response to THCV assessed by functional MRI was not diminished in a study of human volunteers. This suggests that, unlike rimonabant, THCV does not suppress the reward or mood pathways in the brain [12]. 
THCV has potential for the treatment of obesity and impaired glucose tolerance without the adverse events that resulted in the removal of rimonabant from the market. The regulatory position on the components of marijuana is now different from state to state, although marijuana remains illegal at the federal level. Louisiana has a unique system for the control of medical marijuana. It allows non-smoking forms of marijuana and its components but does not permit smoking marijuana [13]. The Louisiana State University (LSU) is a state-appointed grower of marijuana and has partnered with a commercial company to produce oil extracts. Further, a recommendation script for medical marijuana products can only be obtained from stateapproved physicians.

CBD as a treatment for epilepsy has received Food and Drug Administration approval, and initial studies show that THCV holds promise in the treatment of diabetes and obesity. Therefore, the obesity research community must now consider what research questions and study designs will best address the needs in our field. There is a promise that medical marijuana may be part of the solution to the obesity and diabetes epidemic and may offer a safer replacement for rimonabant. Marijuana and its components deserve consideration as a subject for investigation by the obesity research community. Research scientists will need to familiarize themselves with the regulations that are applicable to their state and tailor their studies to the legal framework that best suits each state.

\section{Compliance with ethical standards}

Conflict of interest The authors declare that they have no conflict of interest.

Publisher's note: Springer Nature remains neutral with regard to jurisdictional claims in published maps and institutional affiliations.

\section{References}

1. Sam AH, Salem V, Ghatei MA. Rimonabant: from RIO to ban. J Obes. 2011;2011:432607.
2. Wikipedia contributors. Inverse agonist: Wikipedia, the free encyclopedia; 2019 [updated 8 Jan 2019]. https://en.wikipedia. org/w/index.php?title=Inverse_agonist\&oldid $=877398092$.

3. United States Food \& Drug Administration (FDA). FDA approves first drug comprised of an active ingredient derived from marijuana to treat rare, severe forms of epilepsy. Silver Spring: FDA; 2018. [updated 25 June 2018]. https://www.fda.gov/newsevents/ newsroom/pressannouncements/ucm611046.htm.

4. Merkus FW. Cannabivarin and tetrahydrocannabivarin, two new constituents of hashish. Nature. 1971;232:579-80.

5. Pertwee RG, Thomas A, Stevenson LA, Ross RA, Varvel SA, Lichtman AH, et al. The psychoactive plant cannabinoid, Delta9tetrahydrocannabinol, is antagonized by Delta8- and Delta9tetrahydrocannabivarin in mice in vivo. $\mathrm{Br} \mathrm{J}$ Pharmacol. 2007;150:586-94

6. Thomas A, Stevenson LA, Wease KN, Price MR, Baillie G, Ross RA, et al. Evidence that the plant cannabinoid Delta9tetrahydrocannabivarin is a cannabinoid $\mathrm{CB} 1$ and $\mathrm{CB} 2$ receptor antagonist. Br J Pharmacol. 2005;146:917-26.

7. Riedel G, Fadda P, McKillop-Smith S, Pertwee RG, Platt B, Robinson L. Synthetic and plant-derived cannabinoid receptor antagonists show hypophagic properties in fasted and non-fasted mice. Br J Pharmacol. 2009;156:1154-66.

8. Wargent ET, Zaibi MS, Silvestri C, Hislop DC, Stocker CJ, Stott CG, et al. The cannabinoid Delta(9)-tetrahydrocannabivarin (THCV) ameliorates insulin sensitivity in two mouse models of obesity. Nutr Diabetes. 2013;3:e68.

9. Bluher M, Engeli S, Kloting N, Berndt J, Fasshauer M, Batkai S, et al. Dysregulation of the peripheral and adipose tissue endocannabinoid system in human abdominal obesity. Diabetes. 2006;55:3053-60.

10. Rock EM, Sticht MA, Duncan M, Stott C, Parker LA. Evaluation of the potential of the phytocannabinoids, cannabidivarin (CBDV) and Delta(9)-tetrahydrocannabivarin (THCV), to produce $\mathrm{CB} 1$ receptor inverse agonism symptoms of nausea in rats. $\mathrm{Br} \mathrm{J}$ Pharmacol. 2013;170:671-8.

11. Jadoon KA, Ratcliffe SH, Barrett DA, Thomas EL, Stott C, Bell JD, et al. Efficacy and safety of cannabidiol and tetrahydrocannabivarin on glycemic and lipid parameters in patients with type 2 diabetes: a randomized, double-blind, placebo-controlled, parallel group pilot study. Diabetes Care. 2016;39:177786.

12. Tudge L, Williams C, Cowen PJ, McCabe C. Neural effects of cannabinoid CB1 neutral antagonist tetrahydrocannabivarin on food reward and aversion in healthy volunteers. Int $\mathrm{J}$ Neuropsychopharmacol. 2015;18:1-9.

13. Governing - The states and localities. State marijuana laws in 2018 map. Washington, DC: e.Republic; 2018 [updated 7 Novemeber 2018]. http://www.governing.com/gov-data/safety-justice/ state-marijuana-laws-map-medical-recreational.html. 